\title{
Risk-Reducing Salpingo-Oophorectomy In Brca Mutation Carriers. A prospective multicentric study.
}

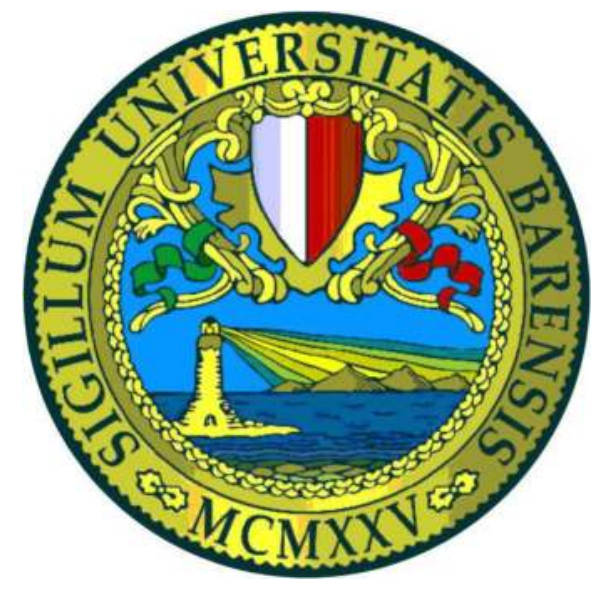

DEL VECCHIO Vittoria, LOIZZI Vera, CICINELLI Ettore, DEROMEMAJ Xheni, KARDHASHI Anila, PARADISO Angelo, LEGGE Francesco, NATALICCHIO Maria Iole, RESTA Leonardo, RESTA Nicoletta and CORMIO Gennaro

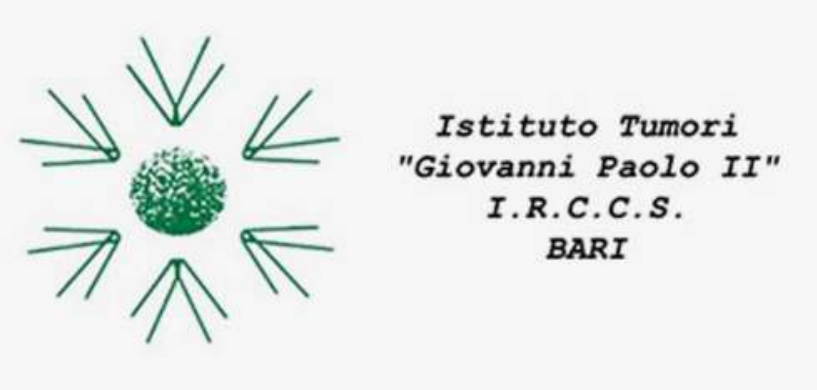

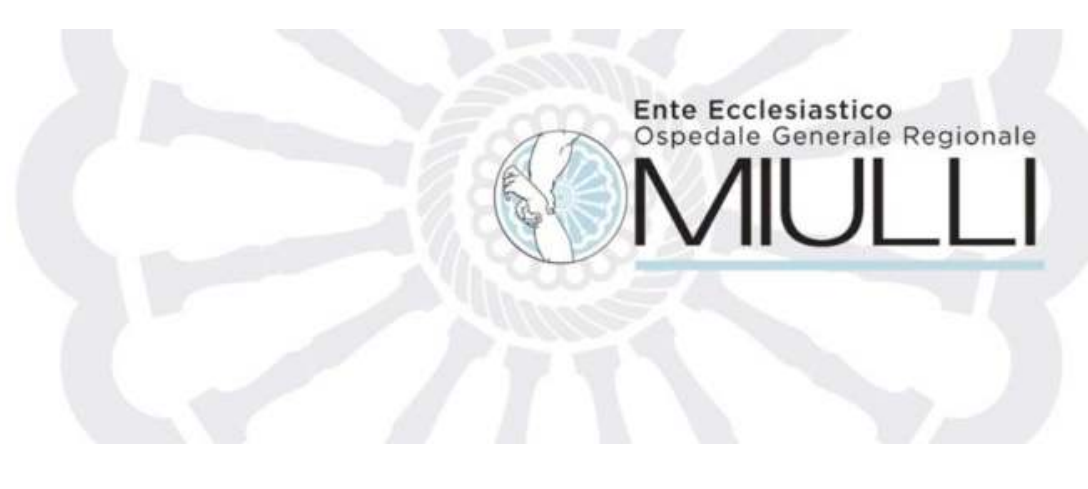

\section{Introduction}

Ovarian carcinoma is the leading cause of death among gynaecological malignancies, and there is a current lack of effective screening procedure. More than one-fifth of ovarian tumours have genetic predisposition and, in about $65-85 \%$ of these cases, the genetic abnormality is related to a germline mutation in Breast Related-Cancer Genes (BRCA) 1 and 2 which are are tumour suppressor-autosomal dominant inherited genes encoding proteins involved in homologous recombination. Different studies evaluated the origin of early High Grade Serous Ovarian Cancer (HGSOC) in the distant portion of the fallopian tube and this discovery led to develop a riskreducing strategy through a prophylactic bilateral salpingo-oophorectomy (BSO) in women with BRCA1/2 genes mutation.

\section{Methodology}

Risk-reducing surgery (RRS) was performed in 74 patients carrying BRCA1 (aged between 34-73 years, median age was 50 years) and BRCA 2 mutation (aged between 41-69 years, median age was 52 years). 39 patients had previous history of breast cancer.

\section{Results}

Between the 74 patients, 58 women $(78,4 \%)$ underwent risk-reducing salpingo-oophorectomy (RRSO) through a laparoscopic minimally invasive approach, 5 (6,7\%) underwent laparoscopic RRSO and contextual hysterectomy, 1 woman $(1,4 \%)$ underwent RRSO through a laparotomic approach and 10 women (13,5\%) laparotomic RRSO and hysterectomy. During $2(2,7 \%)$ laparoscopic RRSO, prophylactic bilateral mastectomy was also performed. Early and late complications occurred in 3 patients (4\%). 2 patients $(2,7 \%)$ were found to have occult Serous Tubal Intraepithelial Carcinoma (STIC) and 3 patients (4\%) occult cancer.

\section{Conclusion}

RRSO is safe and feasible in BRCA mutation carriers. The procedure is effective for genetic prevention of ovarian cancer.
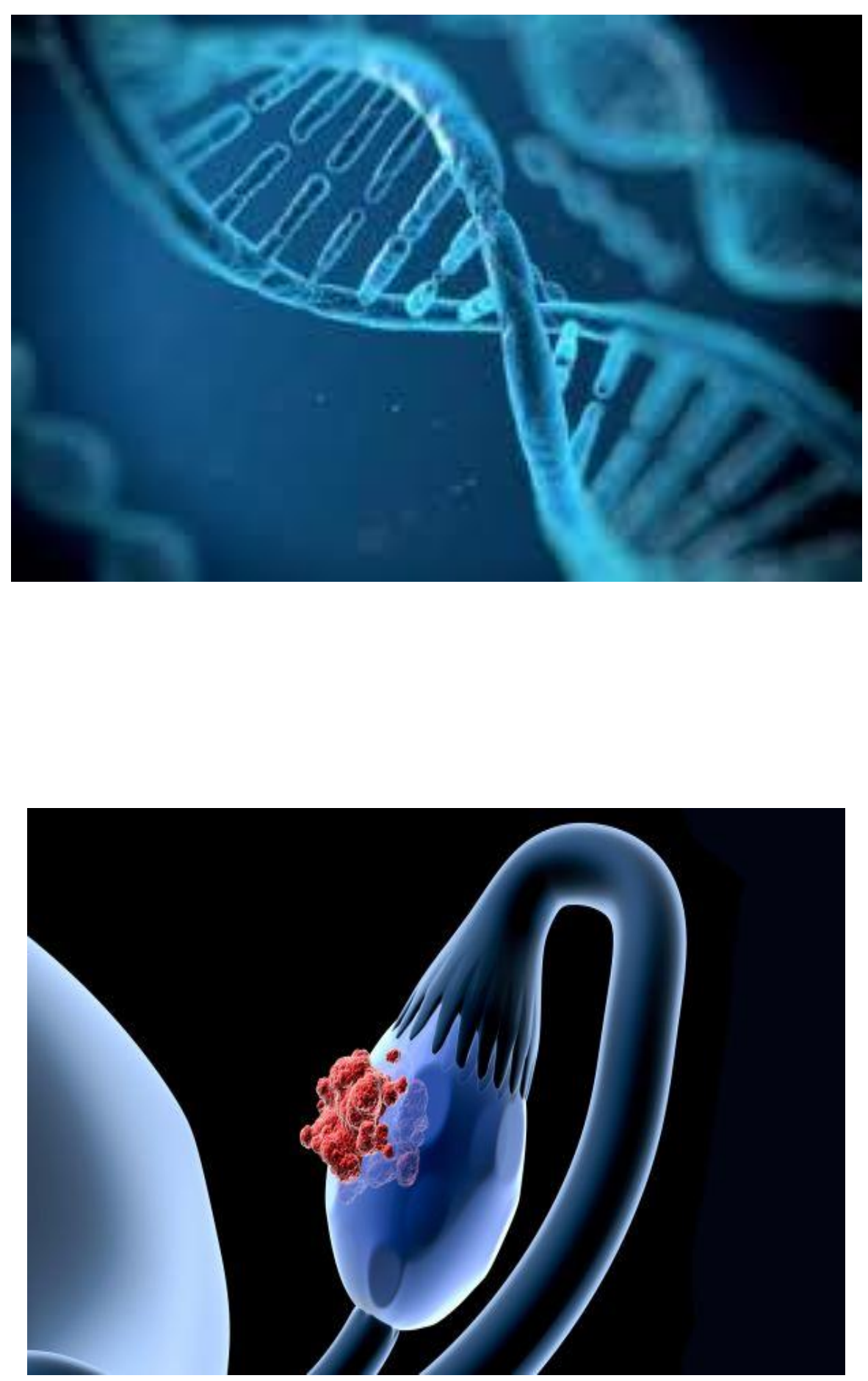

Loizzi V, Cicinelli E, Santamaria F, Murgia F, Minicucci V, Resta L, Resta N, Natalicchio MI, Ranieri G, Cormio G., BRCAmut and "founder effect": a prospective study in a single academic institution., Oncotarget. $2018 \mathrm{Apr}$ 27:9(32):22353-22358

NCCN Guidelines Version 3.2019, BRCA-Related Breast and/or Ovarian Cancer Syndrome.

Bogani G, Tagliabue E, Signorelli M, Chiappa V, Carcangiu ML, Paolini B, et al., Assessing the Risk of Occult Cancer and 30-day Morbidity in Women Undergoing Risk-reducing Surgery: A Prospective Experience., J Minim Invasive Gynecol. 2017 Jul - Aug;24(5):837-842. doi:

10.1016/j.jmig.2017.04.017. Epub 2017 May 4 